\title{
Quality use of medicines within universal health coverage: challenges and opportunities
}

\author{
Anita K Wagner ${ }^{1 *}$, Jonathan D Quick ${ }^{2}$ and Dennis Ross-Degnan ${ }^{1+}$
}

\begin{abstract}
Background: Medicines are a major driver of quality, safety, equity, and cost of care in low and middle-income country health systems. Universal health coverage implementers must explicitly address appropriate use of medicines to realize the health benefits of medicines, avoid wasting scarce resources, and sustain the financial viability of universal health coverage schemes.

Discussion: Medicines are major contributors to the health and well-being of individuals and populations when used appropriately, and they waste resources and endanger health when used unnecessarily or incorrectly. Stakeholders need to balance inherently competing objectives in the pharmaceutical sector. Emerging and expanding UHC schemes provide potential levers to balance competing system objectives.

To use these levers, sustainable universal coverage programs will require a) information systems that can track medicines utilization, expenditures, and quality of medicines use; b) routine monitoring of indicators of medicines availability, access, affordability, and use; c) policies and programs that facilitate appropriate medicines use by prescribers, dispensers, and patients; d) transparency in setting priorities for medicines coverage under resource constraints; and e) a system perspective to engage diverse actors.

As they operationalize paths toward universal health coverage and include targeted medicines coverage policies and programs, systems can build on, and innovate, pharmaceutical policy frameworks and management tools from different countries' settings.

Summary: Ensuring that medicines which achieve important health outcomes are available, accessible to all, used appropriately, and sustainably affordable is essential for realizing universal health coverage. Stakeholder cooperation and use of information and financing system levers provide opportunities to work toward this goal.
\end{abstract}

Keywords: Universal health coverage, Medicines, Pharmaceutical benefit, Financial incentives, Health systems, Quality of care

\section{Background}

On August 15, 2013, WHO Director General Dr. Chan introduced the World Health Report 2013 saying "Universal coverage means quality health care for all delivered in ways that protect users from financial ruin or impoverishment" and highlighted that "[T] he challenge is to expand health services with constant attention to causes of waste and inefficiency that can be reduced through smart policies and wise decisions [1]."

\footnotetext{
* Correspondence: awagner@hms.harvard.edu

${ }^{\dagger}$ Equal contributors

'Department of Population Medicine, Harvard Medical School and Harvard Pilgrim Health Care Institute, 133 Brookline Avenue, Boston, MA 02115, USA Full list of author information is available at the end of the article
}

We argue that UHC implementers must explicitly focus on medicines, which are one of the major drivers of quality, safety, equity, and cost of care in low and middle-income country (LMIC) health systems. We first provide a brief overview of the typical medicines situation in LMICs; second, we describe the competing objectives of pharmaceutical sector policies and suggest that systems striving toward UHC have unique levers at their disposal to balance these objectives; and third, we highlight selected tools and approaches that systems working toward UHC should consider when developing targeted medicines policies and programs. We conclude with key challenges that systems will face as they move toward evidence-informed medicines coverage policies. 


\section{Discussion}

Medicines and UHC - needs and opportunities Medicines in health systems

Medicines are major contributors to the health and wellbeing of individuals and populations when used appropriately, and they waste resources and endanger health when used unnecessarily or incorrectly. Global medicines spending has surpassed US \$1 trillion per year [2] and accounts for up to $67 \%$ of total health expenditures in some countries [3], mostly paid out of pocket by consumers. At the same time, medicines constitute three of the top ten sources of waste of scarce health system resources [4], due, among other factors, to underuse of quality generic products [5]; taxes and tariffs increasing product prices at different levels [6]; unreliable availability of medicines in public sector facilities; [7] substandard and falsified products in markets [8]; and inappropriate use of medicines, including overuse of antibiotics (often for children with respiratory infection or diarrhea) [9] and underuse of proven therapies for chronic conditions (e.g., hypertension, diabetes) $[10,11]$. Meanwhile, households face impoverishment due to paying for medicines [12,13] while patients die prematurely because they lack access to lifesaving medicines [14]. Providing access to novel highcost specialty medicines for prevalent chronic conditions like cancers poses a growing ethical and economic challenge for policy makers in countries at all income levels.

\section{Competing objectives of medicines policies}

Stakeholders need to strike a balance between several competing objectives in the pharmaceutical sector (Figure 1). Ideally, all patients, particularly vulnerable ones, would have access to the medicines they need according to evidence-based treatment guidelines; products would be of proven quality; appropriately prescribed medicines would be available where and when patients need them; and patients would take these medicines as needed to achieve their clinical effects. In this ideal world, both households and the health system would have the resources to pay for necessary medicines, in light of competing demands. To meet national concerns for a strong economy and health security, local manufacturers would be profitable while providing high-quality products at costs that patients and systems could afford. Research-based companies

\section{Ensuring Availability of Quality Generic and Innovative Products}

- Monitoring product quality

- Prequalifying suppliers, products

- Negotiating prices, quality, volume, supply chain security

- Promoting fair competition

- Engaging in risk sharing agreements

- Establishing patient assistance programs

\section{Encouraging Appropriate Use}

- Implementing \& updating standard treatment guidelines (STG)

- Matching essential medicines and reimbursements lists to STG

- Assessing provider performance

- Managing care comprehensively

- Implementing and monitoring policies to encourage clinically appropriate and cost-effective use

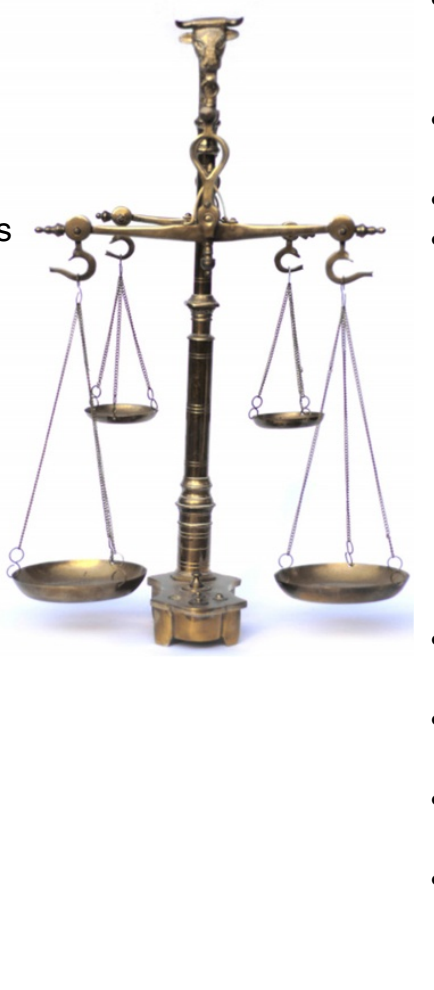

\section{Improving Equitable Access}

- Understanding socioeconomic and geographic disease and utilization profiles

- Assessing household care seeking and barriers to care

- Expanding provider networks

- Targeting policies and programs to improve access for vulnerable populations

\section{Keeping Costs Affordable}

- Monitoring routine medicines expenditures by therapeutic area

- Evaluating health technologies, budget impact drivers

- Assessing household medicines expenditure burden

- Implementing and monitoring policies and programs to reduce waste, inappropriate use

Figure 1 Competing objectives in the medicines sector and selected approaches to balance them. 
would develop innovative products for unmet needs. All stakeholders would adhere to transparent governance and ethical business practices. However, these idealized pharmaceutical sector objectives inevitably compete in many ways. For example, paying for medicines for people who cannot afford them may exceed the resources of systems. Limiting third party payments to preserve the financial sustainability of health systems may increase out-of-pocket household spending for medicines and limit appropriate use [15].

\section{Potential UHC levers to balance objectives}

Emerging and expanding UHC schemes have potential levers to balance competing system objectives. Because they enroll members and pay for their care, schemes could access information on the demographic characteristics, health care needs, and utilization patterns of members. Because they employ or contract with providers, UHC schemes can also know about the demographic characteristics, prescribing patterns, and costs associated with specific providers. In their role as financial intermediaries, UHC schemes have leverage to determine what types of care they pay for and how much they will pay, and they can implement policies that provide incentives for purchasing, prescribing, and using the most clinically appropriate and safe medicines that are known to achieve highly valued health outcomes. Since they pay for large quantities of medicines, UHC schemes are also in a position to negotiate product prices, dictate standards of product quality, react to unethical promotion practices, and demand supply channel efficiency.

Practically, most LMIC insurance schemes do not yet use many of these levers $[16,17]$. Some schemes may not know the demographics and clinical needs of their covered population. Schemes often have inefficient claims processing systems, some based on paper forms, which may make it difficult to access information about medicines utilization in a timely way. Often, schemes limit claims review primarily to detecting instances of fraud. Working actively with members, providers, and manufacturers to set performance standards and shape patterns of pharmaceutical care is currently beyond the scope or capacity of most UHC systems. Historical experience [18] indicates that schemes tend to focus explicitly on medicines only when medicines expenditures threaten the viability of the scheme, and they then focus primarily on prices rather than quality medicines use.

\section{Targeted medicines benefit strategies}

We believe that not every available medicine for every individual could or should be subsidized by a third party payer. Targeted approaches to promote clinically appropriate, cost-effective medicines use require systems to understand populations, clinical conditions, medicines, settings for safe use, costs, and system capacity. Depending on their values, goals, and resources, UHC systems may choose to cover only specific medicines for defined conditions in specific population groups, treated at the lowest system level at which safe and effective care can be provided, and at costs that take into account members' and the system's ability to pay.

Tools and approaches already exist that UHC schemes in LMIC can adapt for use in their settings (Figure 1). International [19] and local data on population disease epidemiology, combined with information on current patterns of care, can help to identify the most important health conditions for which medicines are needed in a given population. Given a set of priority health conditions, evidence-based clinical guidelines [20] can be used to determine the types of medicines needed, which provide a basis for medicine reimbursement lists. Health technology assessment, budget impact analysis, and frameworks for transparency can inform ethically challenging decisions [21] about setting limits on covered therapies. Participation in international product quality assurance collaborations [22] can help ensure product quality, while strengthening capacity for managing medicines in systems [23] can improve the efficiency and reliability of supply. Widely-used facility-based indicators of appropriate and inappropriate medicines use in LMIC [9] could be adapted for use with insurance claims data and expanded to assess medicines use and expenditures for specific conditions.

To ensure financial viability, improve efficiency, and facilitate appropriate use, LMIC insurance systems need to pilot targeted medicines policies that provide incentives to industry, drug distributors, procurement officers, prescribers, dispensers, and patients, to supply and use the most clinically appropriate medicines that achieve valuable health outcomes in an affordable way. Policy approaches, adopted mostly in high-income countries, [24-27] typically address either cost or quality of care. Pay-for-performance programs that financially reward prescribers for achieving performance metrics related to cost or quality and so-called "value-based" coverage policies that reduce the out-of-pocket cost for medicines known to improve health outcomes combine both dimensions. While evidence is mixed on the effects of pay-for-performance and value-based benefit policies in high-income countries, evidence on the impacts of specific medicines benefit policies in LMIC is virtually nonexistent [16].

Given resource limitations, we suggest that most UHC schemes in LMIC consider developing a minimum medicines benefit package that covers a selected list of costeffective first-line medicines for the most prevalent conditions - many of which are essential medicines [28] available as quality generic products. Given member demand and pressure from providers, schemes also need to decide whether and how to cover innovative, high- 
cost medicines that have established clinical value but that may benefit fewer patients. Different tools and approaches are needed to develop a minimum medicines benefit and to make decisions about coverage of specialized high-cost medicines; in both cases, it is crucial for the insurance system to monitor utilization, quality of medicines use, and expenditures.

\section{Key challenges}

\section{Better information}

Information is the single greatest resource that wellfunctioning UHC systems have at their disposal. However, in many systems, data may only be available about medicines expenditures as a component of overall expenditures, and sometimes even that is unmeasured. Without more granular information about which medicines are used, who prescribes them, how they meet the care needs of specific patients, whether they achieve intended population health outcomes, and whether they are fairly and affordably priced, systems striving toward UHC will find it difficult to ensure clinical quality, efficiency, and safety in medicines coverage.
As UHC-targeting schemes expand, they will need to use electronic payment systems. It is crucial that these systems be designed to include the level of detail required to actively manage a medicines benefit. The Table lists illustrative performance indicators in four main pharmaceutical policy domains (Table 1). Routine information systems should allow measurement of these or similar indicators. However, high-end electronic systems take resources and time to develop. In the meantime, other readily available sources of routine data, such as prescriptions and dispensing records at health facilities, can allow stakeholders to generate information needed to make evidence-informed decisions.

In sum, leaders working toward UHC need to strengthen system capacity in benefit design, information technology, pharmaceutical cost analysis, quality measurement, quality assurance, and interpreting routine longitudinal data on medicines availability, access, use, and expenditures.

\section{More patient-centered systems}

Most LMIC health systems were developed primarily to treat acute conditions and provide inpatient care. The

Table 1 Examples of indicators to monitor medicines policies in UHC systems

\begin{tabular}{|c|c|c|}
\hline Domain and question & Sample indicator & Possible data source \\
\hline \multicolumn{3}{|l|}{ Availability of quality generic and innovative products } \\
\hline \multirow{2}{*}{$\begin{array}{l}\text { Does local industry produce a reliable supply } \\
\text { of needed high-quality, low-cost generics? }\end{array}$} & \multirow{2}{*}{$\begin{array}{l}\text { Volume and percent of locally-produced generics } \\
\text { that meet quality and price standards }\end{array}$} & Industry data \\
\hline & & Quality test records \\
\hline $\begin{array}{l}\text { Do risk-sharing strategies between pharmaceutical } \\
\text { companies and payers to provide access to selected } \\
\text { high-cost medicines for selected patients achieve } \\
\text { intended outcomes, and what are unintended ones? }\end{array}$ & $\begin{array}{l}\text { Percent patients with a target conditions who receive an } \\
\text { innovative product that results in expected health benefits }\end{array}$ & $\begin{array}{l}\text { Industry risk sharing program } \\
\text { data }\end{array}$ \\
\hline \multicolumn{3}{|l|}{ Equitable access } \\
\hline Do people receive the medicines they need? & $\begin{array}{l}\text { Percentage of people with a diagnosed chronic illness } \\
\text { who currently have an appropriate medicine available } \\
\text { to treat their condition }\end{array}$ & Household surveys \\
\hline $\begin{array}{l}\text { How does access to appropriate medicines differ } \\
\text { between groups of patients? }\end{array}$ & $\begin{array}{l}\text { Percentage of patients with a given diagnosis who receive a } \\
\text { recommended first-line drug in different subgroups (categorized } \\
\text { by insurance scheme, geographic location, age group, gender, } \\
\text { race and ethnicity, socioeconomic status) }\end{array}$ & $\begin{array}{l}\text { Prescriptions or dispensing } \\
\text { records at health facilities } \\
\text { Insurance claims records }\end{array}$ \\
\hline \multicolumn{3}{|l|}{ Appropriate use } \\
\hline \multirow[t]{2}{*}{ Are we overusing medicines? } & \multirow[t]{2}{*}{ Percentage of primary care patients who receive an antibiotic } & $\begin{array}{l}\text { Prescriptions or dispensing } \\
\text { records at health facilities }\end{array}$ \\
\hline & & Insurance claims records \\
\hline \multirow[t]{2}{*}{ Are we underusing medicines? } & \multirow{2}{*}{$\begin{array}{l}\text { Percentage of patients with a chronic condition } \\
\text { (e.g., diabetes, hypertension) who receive at least } \\
\text { one of the recommended treatments }\end{array}$} & $\begin{array}{l}\text { Prescriptions or dispensing } \\
\text { records at health facilities }\end{array}$ \\
\hline & & Insurance claims records \\
\hline \multicolumn{3}{|l|}{ Affordable costs } \\
\hline $\begin{array}{l}\text { How much does the insurance scheme/health } \\
\text { system spend on medicines? }\end{array}$ & $\begin{array}{l}\text { Medicines expenditures per member per month } \\
\text { (overall, by member category, by specific diagnoses, } \\
\text { by specific therapeutic categories) }\end{array}$ & $\begin{array}{l}\text { Insurance reimbursement } \\
\text { records }\end{array}$ \\
\hline $\begin{array}{l}\text { What is the financial burden associated with } \\
\text { medicines spending in households? }\end{array}$ & $\begin{array}{l}\text { Proportion of patients who indicate that they forego } \\
\text { medicines treatment or spend less on other basic } \\
\text { needs due to medicines costs }\end{array}$ & Household surveys \\
\hline
\end{tabular}


global epidemiologic transition and the increasing need for efficient management of chronic illnesses now dictate that health systems develop ways to provide continuous, affordable, high quality care for life-long illnesses, moving care away from hospitals into the community and taking greater advantage of non-physician providers including nurses, pharmacists, and community health workers. A challenge for UHC-targeting systems will be to link community-based care - such as adherence support at community providers' offices, pharmacies, and homes with insurance financing.

Culture is an important determinant of medicines use. LMIC insurance systems need to develop approaches that promote appropriate traditional treatment and avoid inappropriate care - such as using herbal remedies rather than unnecessary antibiotics to soothe symptoms of upper respiratory tract infections. Social marketing efforts will be required to explain both the concept of insurance, often unfamiliar in LMIC, as well as the rationale for specific medicines benefit policies.

Everywhere, decision makers face challenging ethical questions when setting spending priorities in light of resource constraints. Values, population needs, cultural contexts, the overall health care environment, and other economic and social constraints must factor into decisions. Approaches are certain to change over time, as population needs, technologies, and systems change. Transparency in decision making about medicines coverage [21] and accommodating the preferences of civil society in benefit discussions [29] will be key to maintaining public trust.

Health systems, and the broader national and global systems of which they are a part, are complex and dynamic. Interventions by any one actor will impact the behavior of others. Evaluating the impacts of medicines policies in LMIC will require a system perspective [30] to ensure that the intended and unintended effects of policies are known and inform continued system learning.

\section{Summary}

LMIC working toward UHC have enormous potential to improve health. To succeed, they need to adopt an explicit system focus on sound, evidence-informed medicines policies. We highlight four key pharmaceutical system objectives and outline policy options and essential information needed to achieve them.

\section{Abbreviation \\ UHC: Universal health coverage.}

\section{Competing interests}

We declare the following interests: Since 2007, Drs. Anita Wagner and Dennis Ross-Degnan have conducted regional Medicines and Insurance Coverage Initiative (MedIC) Training Courses in Pharmaceutical Policy Analysis with support from WHO country and regional offices, Harvard University, Harvard Pilgrim Health Care Institute, UK Department for International Development, the Harvard China Fund, Beijing Xuanwu Hospital, Shanghai Shenkang Hospital Development Center, and the Novartis AG. Management Sciences for Health, of which Dr. Jonathan
Quick is the President and CEO, has received grants from the Rockefeller Foundation to promote universal health coverage and from the US Agency for International Development for a project, Systems for Improved Access to Pharmaceuticals and Services.

\section{Authors' contributions}

AKW wrote the first draft of the manuscript, based on published evidence and learning from MedIC pharmaceutical policy analysis courses. DRD and JDQ provided critical input at all stages of the manuscript. All authors read and approved the final manuscript.

\section{Authors' information}

This contribution emerged from decades of efforts by the authors to improve medicines situations in low and middle-income countries. For more than 20 years, AKW and DRD have led research and capacity strengthening activities to contribute to efficient medicines management and sound pharmaceutical policies in systems. Under their Medicines and Insurance Coverage (MedIC) Initiative, they collaborate with health insurance schemes on the path to universal health coverage. JDQ was Director of Essential Drugs and Medicines Policy at the World Health Organization from 1996 to 2004. As President and CEO of Management Sciences for Health, he has guided the first global Dialogue on UHC and Medicines.

\section{Acknowledgments}

We appreciate the sharing of experiences and concerns regarding medicines management and benefits by participants in MedIC Courses in Pharmaceutical Policy Analysis from more than 20 countries and by insurance scheme collaborators in 5 MedIC Asia Study countries. We are grateful for the valuable input on an earlier version of the manuscript from Drs. Maryam Bigdeli, World Health Organization, and Andreas Seiter, World Bank. We thank the two peer reviewers of the manuscript for their constructive feedback.

This paper was developed under the Medicines and Insurance Coverage (MedIC) Initiative without dedicated funding. The Department of Population Medicine, Harvard Medical School and Harvard Pilgrim Health Care Institute supported the Medicines and Insurance Coverage Initiative. The National University of Singapore Yong Loo Lin School of Medicine supported Anita Wagner for a Visiting Research Associate Professorship in 2012/2013 and funded the MedIC Asia study of insurance medicines benefits in 5 countries.

\section{Author details}

${ }^{1}$ Department of Population Medicine, Harvard Medical School and Harvard Pilgrim Health Care Institute, 133 Brookline Avenue, Boston, MA 02115, USA. ${ }^{2}$ Management Sciences for Health, 200 Rivers Edge Drive, Medford, MA 02155, USA.

Received: 18 September 2013 Accepted: 20 August 2014

Published: 27 August 2014

\section{References}

1. Chan M: Remarks at the Launch of the World Health Report 2013: Research for Universal Health Coverage. Beijing; 2013. [Cited 10 September 2013]. Available from: http://www.who.int/dg/speeches/2013/whr_20130815/en/ index.html.

2. IMS Institute for Healthcare Informatics: The global use of medicines. Outlook through 2017. [Cited 22 August 2014]. Available from: http://www. imshealth.com/deployedfiles/imshealth/Global/Content/Corporate/IMS\% 20Health\%20Institute/Reports/Global_Use_of_Meds_Outlook_2017/IIHI_ Global_Use_of_Meds_Report_2013.pdf.

3. Lu Y, Hernandez P, Abegunde D, Edejer T: The World Medicines Situation 2011: Medicine Expenditures. Geneva: World Health Organization. [Cited 22 August 2014]; Available from: http://apps.who.int/medicinedocs/documents/ s18767en/s18767en.pdf.

4. World Health Report: Health Systems Financing: The Path to Universal Coverage. Geneva: World Health Organization; 2010. [Cited 01 April 2013]. Available from: http://www.who.int/whr/2010/en/index.html.

5. Cameron A, Mantel-Teeuwisse AK, Leufkens HG, Laing RO: Switching from originator brand medicines to generic equivalents in selected developing countries: how much could be saved. Value Health 2012, 15(5):664-673.

6. Mendis S, Fukino K, Cameron A, Laing R, Filipe A Jr, Khatib O, Leowski J, Ewen M: The availability and affordability of selected essential medicines for chronic diseases in six low- and middle-income countries. Bull World 
Health Organ 2007, 85(4):279-288. [Cited 22 August 2014]; Available from: http://www.who.int/bulletin/volumes/85/4/06-033647.pdf.

7. Cameron A, Roubos I, Ewen M, Mantel-Teeuwisse AK, Leufkens HG, Laing RO: Differences in the availability of medicines for chronic and acute conditions in the public and private sectors of developing countries. Bull World Health Organ 2011, 89(6):412-421. [Cited 22 August 2014]; Available from: http://www.who.int/bulletin/volumes/89/6/10-084327.pdf.

8. Buckley GJ, Gostin LO: Countering the Problem of Falsified and Substandard Drugs. Washington: Institute of Medicine; 2013. [Cited 21 March 2013]. Available from: http://www.iom.edu/Reports/2013/Countering-the-Problemof-Falsified-and-Substandard-Drugs.aspx.

9. World Health Organization: Medicines use in Primary Care in Developing and Transitional Countries. Fact Book Summarizing Results from Studies Reported Between 1990 and 2006. Geneva: World Health Organization; 2009. [Cited 01 April 2013]. Available from: http://apps.who.int/medicinedocs/documents/ s16073e/s16073e.pdf.

10. Yusuf S, Islam S, Chow CK, Rangarajan S, Dagenais G, Diaz R, Gupta R, Kelishadi R, lqbal R, Avezum A, Kruger A, Kutty R, Lanas F, Lisheng L, Wei L, Lopez-Jaramillo P, Oguz A, Rahman O, Swidan H, Yusoff K, Zatonski W Rosengren A, Teo KK, Prospective Urban Rural Epidemiology (PURE) Study Innvestigators: Use of secondary prevention drugs for cardiovascular disease in the community in high-income, middle-income, and low-income countries (the PURE Study): a prospective epidemiological survey. Lancet 2011, 378(9798):1231-1242.

11. Bowry AD, Shrank WH, Lee JL, Stedman M, Choudhry NK: A systematic review of adherence to cardiovascular medications in resource-limited settings. J Gen Intern Med 2011, 26(12):1479-1491.

12. Shahrawat R, Rao KD: Insured yet vulnerable: out-of-pocket payments and India's poor. Health Policy Plan 2012, 27(3):213-221.

13. Yip W, Hsiao W: Non evidence-based policy: How effective is China's new cooperative medical scheme in reducing medical impoverishment? SoC Sci Med 2009, 68(2):201-209.

14. UN Commission on Life-Saving Commodities for Women and Children: Commissioner's report. 2012. [Cited 01 June 2013]. Available from: http:// www.unicef.org/media/files/UN_Commission_Report_September_2012_ Final.pdf.

15. Piette JD, Heisler M, Wagner TH: Problems paying out-of-pocket medication costs among older adults with diabetes. Diabetes Care 2004, 27(2):3-391. doi:10.2337/diacare.27.2.384

16. Faden L, Vialle-Valentin C, Ross-Degnan D, Wagner AK: Active pharmaceutical management strategies of health insurance systems to improve costeffective use of medicines in low- and middle-income countries: a systematic review of current evidence. Health Policy 2011, 100:134-143,

17. Carapinha J, Ross-Degnan D, Desta A, Wagner AK: Health insurance systems in five Sub-Saharan African countries: medicines benefits and data for decision making. Health Policy 2011, 99:193-202.

18. Backliwal A, Mani S: Navigating the new Thailand, IMS Asia Pacific Insight 2011. 2011. 1:12-15. [Cited 22 August 2014]; Available from: http://www. imshealth.com/deployedfiles/ims/Global/Asia\%20Pacific/2011_Magazine Asia_softcopy\%20FINAL.pdf.

19. World Health Organization: Global Health Observatory. [Cited 01 June 2013]. Available from: http://www.who.int/gho/en/.

20. National Institute for Health and Care Excellence: Published clinical guidelines. [Cited 01 June 2013]. Available from: http://www.nice.org.uk/ guidance/cg/published/index.jsp?p=off.

21. Various authors (BMJ Special Section): Moving forward on rationing. BMJ 2008, 337:903-906.

22. World Health Organization: Quality assurance and safety of medicines: Main challenges and strategic direction. [Cited 01 June 2013]. Available from: http://www.who.int/medicines/about/qsm_strategy/en/

23. Management Sciences for Health: MDS-3: Managing access to medicines and health technologies (MDS-3). Arlington, VA: Management Sciences for Health; 2012. [Cited 22 August 2014]. Available from: http://www.msh.org/ resources/mds-3-managing-access-to-medicines-and-health-technologies.

24. Aaserud M, Dahlgren AT, Kösters JP, Oxman AD, Ramsay C, Sturm H: Pharmaceutical policies: effects of reference pricing, other pricing, and purchasing policies. Cochrane Database Syst Rev 2006, 19(2):CD005979.

25. Austvoll-Dahlgren A, Aaserud M, Vist G, Ramsay C, Oxman AD, Sturm H, Kösters JP, Vernby A: Pharmaceutical policies: effects of cap and co-payment on rational drug use. Cochrane Database Syst Rev 2008, 23(1):CD007017.
26. Sturm $H$, Austvoll-Dahlgren $A$, Aaserud M, Oxman AD, Ramsay C, Vernby A, Kösters JP: Pharmaceutical policies: effects of financial incentives for prescribers. Cochrane Database Syst Rev 2007, 18(3):CD006731.

27. Lu CY, Ross-Degnan D, Soumerai SB, Pearson S-A: Interventions designed to improve the quality and efficiency of medication use in managed care: a critical review of the literature - 2001-2007. BMC Health Serv Res 2008, 8(1):75.

28. World Health Organization: Essential medicines [Cited 11 July 2013]. Available from: http://www.who.int/topics/essential_medicines/en/.

29. Linley WG, Hughes DA: Societal views on NICE, cancer drugs fund, and value-based pricing criteria for prioritising medicines: a cross-sectional survey of 4118 adults in Great Britain. Health Econ 2013, 22:948-964.

30. Adam T, De Savigny D: Systems thinking for health systems strengthening in LMICs: seizing the opportunity. Health Policy Plann 2012, 27(Suppl 4):iv1-iv66.

doi:10.1186/1472-6963-14-357

Cite this article as: Wagner et al:: Quality use of medicines within universal health coverage: challenges and opportunities. BMC Health Services Research 2014 14:357.

\section{Submit your next manuscript to BioMed Central and take full advantage of:}

- Convenient online submission

- Thorough peer review

- No space constraints or color figure charges

- Immediate publication on acceptance

- Inclusion in PubMed, CAS, Scopus and Google Scholar

- Research which is freely available for redistribution 